\title{
The Impact of Therapeutic Improvements in Reducing Peptic Ulcer Mortality in Europe
}

\author{
CARLO LA VECCHIA***, FRANCA LUCCHINI*, EVA NEGRI**, VALERIO REGGI ${ }^{\dagger}$ AND \\ FABIO LEVI":
}

\begin{abstract}
La Vecchia C (Institut Universitaire de Médecine Sociale et Préventive, Bugnon 17, 1005 Lausanne, Switzerland), Lucchini F, Negri E, Reggi $V$ and Levi F. The impact of therapeutic improvements in reducing peptic ulcer mortality in Europe. International Journal of Epidemiology 1993; 22: 96-108.

Trends in death certification rates from peptic ulcer between 1955 and 1989 have been analysed for 24 European countries on the basis of age-specific and age-standerdized rates, and a log-linear model to estimate the effects of age, cohort of birth and period of death. For males, in all Western countries there were substantial declines in mortality. In the late 1950s, the range of variation of the world standardized rates was between 4/100 000 in France and 17.8 in Portugal. In the late 1980 s, only Ireland had a rate over $5 / 100000$, and values for most Western countries ranged between 2 and 4/100000. The average fall in rates over the last three decades was 56\%. Of this, a high proportion (45\%) was registered between 1975 and 1984. In Eastern Europe, no systematic change was observed until the earty 1970 s, but over the last 15 years peptic ulcer mortality declined by an average of 20\%. In 1985-1989 the lowest rate was $4.5 / 100000$ in Bulgaria, and for all other countries peptic ulcer mortality ranged between 5 and $7.2 / 100000$. Peptic ulcer mortality was substantially lower in females, and showed no appreciable modification in Western Europe, and several increases in Eastern Europe until the mid 1970s. Thereafter, mortality declined by an overall $25 \%$ in the West and $15 \%$ in the East. Earlier declines for males in Western Europe were chiefly related to a cohort effect, reflecting more favourable risk factor exposure (such as diet, Helicobacter pyfori or smoking) of subsequent generations. The recent falls, in contrast, were mainly on a period of death basis indicating therapeutic advancements (including the introduction of $\mathrm{H}_{2}$-receptor-antagonists in the mid-1970s) as the major determinant. These falls correspond to about 20000 deaths from peptic ulcer avoided every year in the whole of Europe.
\end{abstract}

Peptic ulcer had become a major public health problem and a common cause of death by the middle of the current century. The rates had been rising in most developed countries during the first half of the century. ${ }^{1,2}$

Thereafter, however, ulcer rates have started to decline, mainly on a cohort of birth basis, i.e. starting from younger generations. ${ }^{3-13}$ This trend pattern probably reflects favourable changes in exposure to risk factors (such as diet, smoking and infectious agents) in more recent generations.

Important downward trends in peptic ulcer mortality were also observed from the late 1970 s, following the introduction of effective therapies (mainly histamine-2( $\left.\mathrm{H}_{2}\right)$-receptor-antagonists). These rate

\footnotetext{
* Institut Universitaire de Mtdecine Sociale et Preventive, Bugnon 17, 1005 Lausanne, Switzerland.

** Istituto di Ricetche Farmacologiche 'Mario Negn', via Eritrea 62, 20157 Milano, Italy.

$\dagger$ Division of Drug Management and Policies, WHO, av. Appis 20, 1211 Geneva 27, Switzerland.

$\ddagger$ Registre Vaudois des Tumeurs, CHUV - Falaises 1, 1011 Lausanne, Switzerland.
}

changes were, therefore, mainly on a period of death basis, since these therapies favourably affected ulcer mortality during the same calendar period for various age groups. ${ }^{13-15}$

To understand further the underlying determinants of peptic ulcer mortality trends, this article will summarize changes in mortality in various European countries between the late 1950s and the mid 1970s (i.e. before the introduction of effective therapies), and thereafter, i.e. up to the late 1980 s. The related impact in terms of public health and estimated numbers of avoided deaths will also be evaluated and discussed.

\section{MATERIALS AND METHODS}

Death certification numbers from peptic ulcer, stratified for sex and 5-year age groups for 24 European countries (excluding a few small countries like Iceland, Luxembourg, Malta, Liechtenstein etc.), were derived from copies of the original computer tapes of the World Health Organization (WHO) database.

During the calendar period considered (1955-1989), four different revisions of the International Classifica- 
tion of Diseases (ICD) ${ }^{16-19}$ were used. Classification of peptic ulcer deaths was recoded according to the Ninth Revision of the ICD. Gastric ulcer (ICD 540 in the Sixth and Seventh Revisions; ICD 531 in the Eighth and Ninth) duodenal ulcer (ICD 541 in the Sixth and Seventh Revisions; ICD 532 in the Eighth and Ninth), gastrojejunal ulcer (ICD 542 in the Sixth and Seventh Revisions; ICD 534 in the Eighth and Ninth), and gastroduodenal ulcer (ICD 533 in the Eighth and Ninth Revisions) were grouped together on account of difficulties in the interpretation of potential changes in classification and death certification reliability.

Estimates of the resident population, generally based on official censuses, were obtained from the same WHO databank. From the matrices of certified deaths and resident populations, age-standardized rates (on the World standard population) were computed. Besides overall age-adjusted rates, truncated ones at age 35-64 were chosen for presentation. Truncated rates are of interest for at least two reasons; since: i) they provide information specifically on trends in middle age, and ii) death certification in the elderly is generally less reliable, and may therefore introduce spurious trends in rates.

In a few countries, data were missing for part of one or more calendar periods. When a single year was missing within a quinquennium, numerators and denominators were interpolated linearly for the previous and subsequent calendar years. No extrapolation was made for missing data at the beginning or the end of the calendar period considered, or when data on one or more quinquennia were not available.

Further, an age, period and cohort model with arbitrary constraints on the parameters was applied to the matrices of age-specific rates between 25 and 79 years.

For the purpose of model fitting deaths among those aged over 79 were not considered, since death certification is known to be less accurate in older age groups. We chose 25 as the lower age limit, to reduce the problem of random variation due to small numbers. Cohorts were defined according to the central year of birth. For instance, the earliest possible cohort considered (the 1880 cohort) relates to people aged 75-79 who died in the quinquennium 1955-1959: they could have been born in any of 10 years from 1875 to 1885 inclusive.

The method was derived from that proposed by Osmond and Gardner, ${ }^{20}$ and has been previously described. ${ }^{21}$ Briefly, from the matrices of age-specific death rates for each 5-year calendar period and age group, the effect of age, birth cohort and period of death was evaluated through a log-linear Poisson model, fitted using the Generalized Linear Interactive Modelling (GLIM) procedure ${ }^{22}$ with appropriate usersupplied macros. ${ }^{21}$ In simplified terms, the estimates presented are derived from the model including the three factors (age/cohort/period) which minimizes the sum of the Euclidean distances from the three possible two-factor models (age/period; age/cohort; period/ cohort). Cohort and period of death values were averaged to unity; the age values are interpretable in terms of mean age-specific death rates in the period considered. Cohort values related to earlier and more recent periods are based on fewer age-specific rates (e.g. only one for the 1885 cohort, two for 1890 , etc.) and hence are less stable and reliable than central ones.

\section{RESULTS}

Table 1 gives the overall death certification rates from peptic ulcer in males for three selected calendar quinquennia, 1955-1959, 1970-1974 and 1985-1989 in 16 Western European and eight Eastern European countries. In all Western countries there were substantial declines in mortality. In the late 1950 s, the range of variation of overall standardized rates was between 4.0/100 000 in France and 17.8/100 000 in Portugal. In the early 1970 s, the lowest rate was in Norway $(3.8 / 100000)$ and the highest again in Portugal $(10.6 / 100000)$. In the late 1980 s, only Ireland had a rate over 5.0/100 000, and values for most Western European countries were $2-4 / 100000$. The average fall in rates over the last three decades was $56 \%$. Of this, the largest part $(45 \%)$ was registered between 1975 and 1988.

In Eastern Europe, peptic ulcer mortality in 1955-1959 ranged between 6.5/100000 in Czechoslovakia and $9.9 / 100000$ in Romania. No systematic change was observed until the early 1970 s, but over the last 15 years rates declined by an average of 20\%. For 1985-1989 the lowest rate (for Bulgaria) was $4.5 / 100000$, and for all other countries male peptic ulcer mortality was $5-7.2 / 100000$.

The pattern was similar, but the proportional falls were larger, when only truncated rates for 35-64 year olds were considered (Table 2). In Western Europe appreciable declines were already observed in the earlier calendar period, but these became more pronounced over recent years. The overall average fall between 1955 and 1989 was $74 \%$, and most of this fall $(64 \%)$ was registered after 1975. In Eastern Europe there was no appreciable trend in earlier calendar periods, but peptic ulcer mortality declined by approximately $25 \%$ from 1975 onwards.

Peptic ulcer mortality was substantially lower in females (Table 3). In 1955-1959 the range of variation 
TABLE I Overall death certification rates per 100000 males from peptic ulcer in selected European countries, $1955-1989$

\begin{tabular}{|c|c|c|c|c|c|}
\hline \multirow{2}{*}{ Country } & \multicolumn{3}{|c|}{ Mortality rates per 100000 males in } & \multicolumn{2}{|c|}{ Th change in rates } \\
\hline & $1955-1959$ & $1970-1974$ & $1985-1989$ & $\begin{array}{c}1985-1989 \text { vs. } \\
1955-1959\end{array}$ & $\begin{array}{c}1985-1989 \text { vs. } \\
1970-1974\end{array}$ \\
\hline \multicolumn{6}{|l|}{ Western Europe } \\
\hline Austria & 8.7 & 8.4 & 4.4 & -49 & -48 \\
\hline Belgium & 5.7 & 4.7 & 2.4 & -58 & -49 \\
\hline Denmark & 6.6 & 5.8 & 4.6 & -30 & -21 \\
\hline Finland & 8.9 & 4.8 & 4.2 & -53 & -13 \\
\hline France & 4.0 & 4.3 & 2.8 & -30 & -35 \\
\hline Germany, FRG & 8.1 & 7.3 & 3.1 & -62 & -58 \\
\hline Greece & 7.5 & 4.2 & 2.1 & -72 & $-\$ 0$ \\
\hline Ireland & 10.0 & 7.8 & 5.4 & -46 & -31 \\
\hline Italy & 8.9 & 9.3 & 3.2 & -64 & -66 \\
\hline Netherlands & 7.0 & 4.6 & 2.3 & -67 & -50 \\
\hline Norway & 4.4 & 3.8 & 3.3 & -25 & -13 \\
\hline Portugal & 17.8 & 10.6 & 3.4 & -81 & -68 \\
\hline Spain & 8.6 & 8.2 & 2.8 & -67 & -66 \\
\hline Sweden & 8.1 & 7.8 & 3.4 & -58 & -96 \\
\hline Switzerland & 7.8 & 5.6 & 2.4 & -69 & -57 \\
\hline UK & 12.4 & 7.1 & 4.9 & -60 & -31 \\
\hline \multicolumn{6}{|l|}{ Eastern Europe } \\
\hline Bulgaria & - & 6.4 & 4.5 & - & -30 \\
\hline Czechoslovakia & 6.5 & 6.9 & 5.6 & -14 & -19 \\
\hline Germany, GDR & - & 9.2 & 6.3 & - & -32 \\
\hline Hungary & 7.8 & 9.3 & 7.2 & -8 & -23 \\
\hline Poland & 7.7 & 8.5 & 6.0 & -22 & -29 \\
\hline Romania & 9.9 & 5.0 & 5.2 & -47 & +4 \\
\hline USSR & - & - & 5.7 & - & - \\
\hline Yugoslavia & - & 7.0 & 6.5 & - & -7 \\
\hline
\end{tabular}


TABLE 2 Truncated 35-64 year death cerification rates per 100000 males from peptic ulcer in selected European countries, $1955-1959$ to $1985-1989$

\begin{tabular}{|c|c|c|c|c|c|}
\hline \multirow{2}{*}{ Country } & \multicolumn{3}{|c|}{ Mortality rates per 100000 males in } & \multicolumn{2}{|c|}{7 change in rates } \\
\hline & $1955-1959$ & $1970-1974$ & $1985-1989$ & $\begin{array}{c}1985-1989 \text { vs } \\
1955-1959\end{array}$ & $\begin{array}{c}1985-1989 \text { vs } \\
1970-1974\end{array}$ \\
\hline \multicolumn{6}{|l|}{ Western Europe } \\
\hline Austria & 13.7 & 10.5 & 4.4 & -68 & -58 \\
\hline Belgium & 9.8 & 5.3 & 2.0 & -80 & -62 \\
\hline Denmark & 10.0 & 5.9 & 3.4 & -66 & -42 \\
\hline Finland & 15.5 & 6.5 & 4.4 & -72 & -32 \\
\hline France & 6.7 & 5.8 & 2.5 & -63 & -57 \\
\hline Germany, FRG & 16.0 & 10.9 & 2.9 & -82 & -73 \\
\hline Greece & 9.8 & 4.0 & 1.8 & -82 & -55 \\
\hline Ireland & 17.7 & 8.1 & 4.2 & -76 & -48 \\
\hline Italy & 18.0 & 13.3 & 2.7 & -85 & -80 \\
\hline Netherlands & 10.5 & 5.1 & 1.6 & -85 & -69 \\
\hline Norway & 7.3 & 4.6 & 2.4 & -67 & -48 \\
\hline Portugal & 31.8 & 15.1 & 3.5 & -89 & -77 \\
\hline Spain & 14.8 & 11.0 & 2.4 & -84 & -78 \\
\hline Sweden & 11.9 & 6.9 & 2.8 & -76 & -59 \\
\hline Switzerland & 10.6 & 6.3 & 1.7 & -84 & -73 \\
\hline UK & 15.8 & 7.1 & 4.0 & -75 & -44 \\
\hline \multicolumn{6}{|l|}{ Eastern Europe } \\
\hline Bulgaria & - & 8.8 & 6.6 & - & -25 \\
\hline Czechoslovakia & 10.7 & 9.6 & 8.3 & -22 & -14 \\
\hline Germany, GDR & - & 12.3 & 8.2 & - & -33 \\
\hline Hungary & 13.3 & 12.9 & 11.0 & -17 & -15 \\
\hline Poland & 14.1 & 12.7 & 8.5 & -40 & -33 \\
\hline Romania & 18.4 & 9.3 & 9.4 & -49 & +1 \\
\hline USSR & - & - & 10.4 & - & - \\
\hline Yugoslavia & - & 10.9 & 6.9 & - & -37 \\
\hline
\end{tabular}


TABLE 3 Overall death certification rales per 100 000 females from peptic ulcer in selected European countries, $1955-1959101985-1989$

\begin{tabular}{|c|c|c|c|c|c|}
\hline \multirow{2}{*}{ Country } & \multicolumn{3}{|c|}{ Mortality rates per 100000 females in } & \multicolumn{2}{|c|}{ to change in rates } \\
\hline & $1955-1959$ & $1970-1974$ & $1985-1989$ & $\begin{array}{c}1985-1989 \text { vs. } \\
1955-1959\end{array}$ & $\begin{array}{c}1985-1989 \text { vs } \\
1970-1974\end{array}$ \\
\hline \multicolumn{6}{|l|}{ Westem Europe } \\
\hline Austria & 3.0 & 3.1 & 2.4 & -20 & -23 \\
\hline Belgium & 1.0 & 1.7 & 1.2 & +20 & -29 \\
\hline Denmark & 2.4 & 2.7 & 3.2 & +33 & +19 \\
\hline Finland & 1.8 & 2.0 & 2.0 & +11 & - \\
\hline France & 0.8 & 1.1 & 1.1 & +38 & - \\
\hline Germany, FRG & 1.5 & 2.1 & 1.6 & +7 & -24 \\
\hline Greece & 2.4 & 1.5 & 0.9 & -63 & -40 \\
\hline Ireland & 3.1 & 3.4 & 2.5 & -19 & -26 \\
\hline Italy & 1.6 & 1.9 & 1.1 & -31 & -42 \\
\hline Netherlands & 2.1 & 1.9 & 1.3 & -38 & -32 \\
\hline Norway & 1.4 & 1.5 & 1.6 & +14 & +7 \\
\hline Portugal & 3.2 & 2.5 & 1.2 & -63 & -52 \\
\hline Spain & 1.8 & 1.9 & 1.0 & -44 & -47 \\
\hline Sweden & 3.1 & 3.5 & 1.8 & -42 & -49 \\
\hline Switzerland & 3.0 & 2.4 & 1.4 & -53 & -42 \\
\hline UK & 3.5 & 2.8 & 3.1 & -11 & +11 \\
\hline \multicolumn{6}{|l|}{ Eastern Europe } \\
\hline Bulgaria & 1.7 & 1.9 & 1.4 & -18 & -26 \\
\hline Czechoslovakia & 1.7 & 2.2 & 2.0 & +18 & -9 \\
\hline Germany, GDR & - & 2.9 & 2.5 & - & -14 \\
\hline Hungary & 1.9 & 3.3 & 3.1 & +63 & -6 \\
\hline Poland & 1.8 & 2.2 & 2.0 & +11 & $\rightarrow$ \\
\hline Romania & 2.3 & 1.3 & 1.3 & -45 & - \\
\hline USSR & - & - & 1.2 & - & - \\
\hline Yugoslavia & - & 2.4 & 1.9 & - & -21 \\
\hline
\end{tabular}


was between $0.8 / 100000$ in France and 3.5/100 000 in the UK. No appreciable modification was observed until the early 1970s, but from 1975 to 1989 overall peptic ulcer rates declined by approximately $25 \%$. In Eastern Europe the rates in the 1950s were comparable (i.e. between $1.7 / 100000$ in Bulgaria and Czechoslovakia and $2.3 / 100000$ in Romania). Most countries showed upward trends between 1955 and 1974, followed by subsequent declines. Thus, rates in the late 1980 s were about $15 \%$ lower than those registered three decades earlier.

Systematic differences between Western and Eastern Europe were also evident for females on inspection of truncated rates (35-64 years, Table 4). Peptic ulcer mortality rates in middle aged women started from comparable values in the late 1950 s for the two areas of the continent (i.e. a round $2-3 / 100000$ in most countries), but the decline was much greater in Western Europe, averaging $63 \%$ between 1955 and 1989 , and $50 \%$ over the last 15 years alone. In Eastern Europe, the decline was only about $20 \%$.
Figure 1 summarizes the range of variation in peptic ulcer mortality in various European countries over the last calendar period (1985-1989). Figure 2 gives trends in age-standardized (all age and truncated) rates in the four largest Western and the four largest Eastern European countries.

Figure 3 gives the estimates from the age, period and cohort model for the same countries, excluding Yugoslavia (where data for 1955-1959 were not available).

In the four Western countries the peak in the cohort effect for males was registered between 1890 in the UK and 1900-1910 in France, Germany and Italy, and the decline in rates for the most recent cohorts (born in 1960 ) was substantial, with a value of $0.20-0.03$ (i.e. with a reduction from $80 \%$ to over $95 \%$ ) as compared to the weighted average of all cohort values. The fall in cohort values started later in Eastern European countries, particularly in Hungary, and the value for the youngest generation ranged between 0.4 (in Czechoslovakia and Poland) and 0.55 in Hungary, i.e. the

TABLE 4 Truncated 35-64 years death certfication rates per 100 000 females from peptic ulcer in selected European countries, $1955-1959$ to $1985-1989$

\begin{tabular}{|c|c|c|c|c|c|}
\hline \multirow{2}{*}{ Country } & \multicolumn{3}{|c|}{ Mortality rates per 100000 females in } & \multicolumn{2}{|c|}{ \%o change in rates } \\
\hline & $1955-1959$ & $1970-1974$ & $1985-1989$ & $\begin{array}{c}1985-1989 \text { vs. } \\
1955-1959\end{array}$ & $\begin{array}{c}1985-1989 \text { v3 } \\
1970-1974\end{array}$ \\
\hline \multicolumn{6}{|l|}{ Western Europe } \\
\hline Austria & 3.3 & 2.9 & 1.7 & -48 & -41 \\
\hline Belgium & 1.1 & 1.2 & 0.3 & -73 & -75 \\
\hline Denmark & 3.0 & 2.5 & 2.7 & -10 & +8 \\
\hline Finland & 2.2 & 1.8 & 1.3 & -41 & -28 \\
\hline France & 0.8 & 0.9 & 0.6 & -25 & -33 \\
\hline Germany, FRG & 2.1 & 2.3 & 1.0 & -52 & -57 \\
\hline Greece & 1.7 & 0.9 & 0.5 & -71 & -44 \\
\hline Ireland & 4.6 & 3.6 & 1.1 & -76 & -69 \\
\hline Italy & 2.2 & 1.9 & 0.6 & -73 & -68 \\
\hline Netherlands & 2.0 & 1.3 & 0.6 & -70 & -54 \\
\hline Norway & 1.6 & 1.2 & 0.7 & -56 & -42 \\
\hline Portugal & 5.6 & 2.5 & 0.9 & -84 & -64 \\
\hline Spain & 2.3 & 1.6 & 0.4 & -83 & -75 \\
\hline Sweden & 3.4 & 2.4 & 0.9 & -74 & -63 \\
\hline Switzerland & 2.8 & 1.6 & 0.6 & -79 & -63 \\
\hline UK & 3.4 & 2.4 & 2.1 & -38 & -13 \\
\hline \multicolumn{6}{|l|}{ Eastern Europe } \\
\hline Bulgana & 1.8 & 2.0 & 1.2 & -33 & -40 \\
\hline Czechoslovakia & 2.3 & 2.1 & 2.1 & -9 & - \\
\hline Germany, GDR & - & 3.1 & 2.5 & - & -19 \\
\hline Hungary & 2.4 & 3.4 & 3.2 & +33 & -6 \\
\hline Poland & 3.2 & 2.8 & 2.3 & -28 & -18 \\
\hline Romania & 3.2 & 2.1 & 1.8 & -44 & -14 \\
\hline USSR & - & - & 1.6 & - & - \\
\hline Yugoslavia & - & 3.0 & 1.8 & - & -40 \\
\hline
\end{tabular}



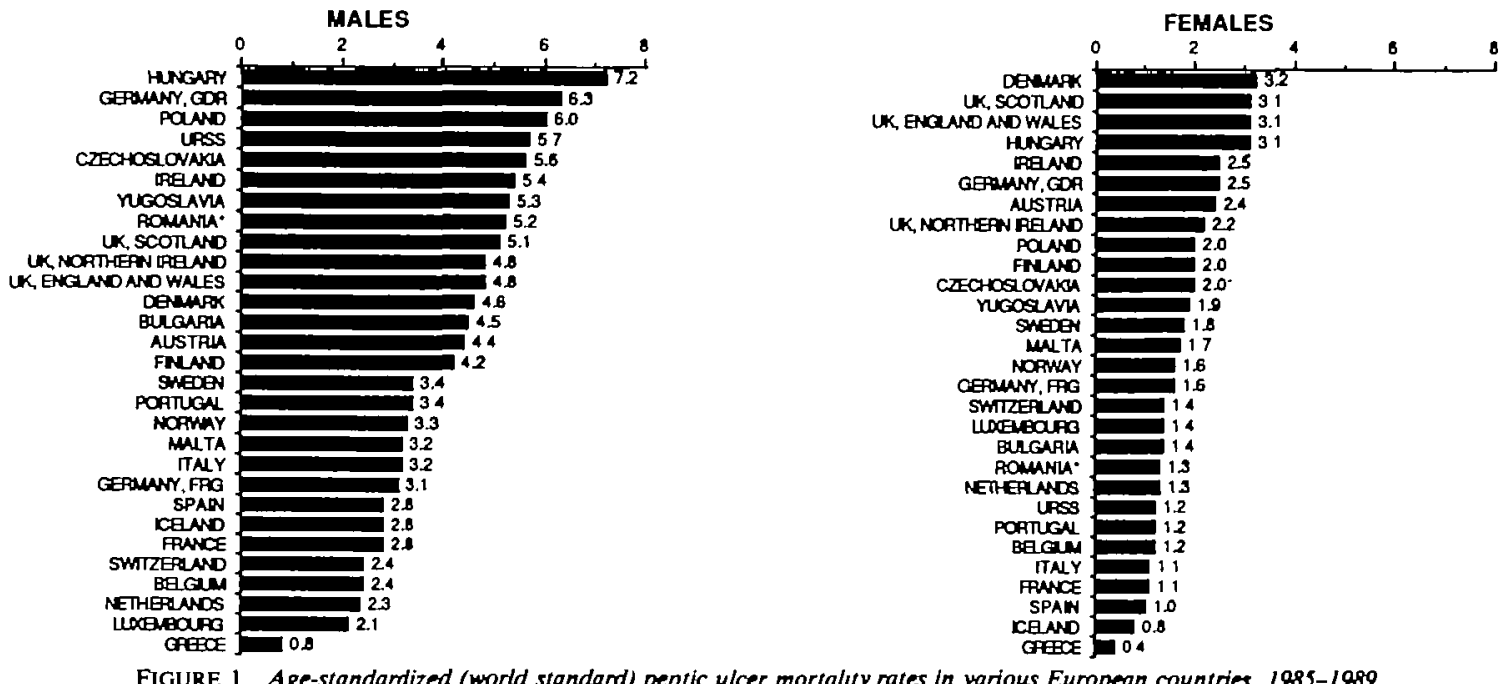

FIGURE 1 Age-standardized (world standand) peptic ulcer mortality rates in warious European countries, $1989-1989$

estimated decline was $45-60 \%$. In the UK, the period effect showed a steady decline, but in all other countries appreciable falls only became evident from the mid-1970s. The declines in period values were earlier and steeper in Western than in Eastern Europe.

Among females, the peak values for cohort effects were observed between 1910 and 1930 in the four Western European countries considered, and the declines were appreciable (from $50 \%$ in France to over $80 \%$ in other countries). Of the three Eastern European countries, only Poland showed some fall in the cohort effect, starting from 1940 onwards. No considerable change was observed in Czechoslovakia, (except in the last cohort) and cohort values increased in Hungary. As in males, the estimated relative decline in period of death values over the last one or two decades was greater in Western than in Eastern Europe.

\section{DISCUSSION}

This overview of trends in peptic ulcer mortality in various European countries documents and quantifies the major declines observed in peptic ulcer mortality during the last four decades.

A possible explanation for these declines in mortality rates could be an artefact resulting from changes in coding and diagnostic accuracy. These analyses and inferences are, in fact, based on official death certifications which, to a variable extent, are subject to problems of reliability and validity. To reduce these problems, we pooled all deaths attributed to peptic ulcer (gastric, duodenal, and unspecified). However, changes in accuracy of diagnosis and certification in various countries are unlikely to explain, largely or wholly, such a consistent and substantial fall in mortality rates.
Substantial differences were evident in the two sexes and between Western and Eastern Europe, since for males in most Western European countries peptic ulcer mortality was already declining between the 1950 s and the 1970s, and this decline was greater in the last decade. Rates were stable-or moving upwards-for males in Eastern Europe up to the late 1970s and some decline was only evident during the last decade. For females, ulcer mortality between the 1950s and the mid-1970s did not show appreciable and systematic changes in any area of the continent, but recent declines were greater in Western than in Eastern Europe.

Earlier declines for males in Western countries were chiefly related to a cohort effect, since rates had started to decline from younger generations. ${ }^{6-9,15}$ This probably reflects more favourable patterns of exposure to risk factors for ulcer (such as diet, Helicobacter pylori or other infectious agents, and smoking) in each subsequent generation. ${ }^{2,9}$ These downward trends were not observed in Eastern European countries, whose fall in cohort values were later and more moderate, and whose rates did not appreciably change until the mid-1970s for males, and, if anything, increased for females, indicating, that, in these countries, there was no earlier favourable modification in risk factor exposure. The recent falls, in contrast, were mainly on a period of death basis. This indicates that the main underlying determinant is related to therapeutic advancements, which affected in a similar calendar period and to a comparable extent subjects of different ages. The introduction of $\mathrm{H}_{2}$-receptor-antagonists in the late 1970 s is probably the main determinant of the recent substantial declines 

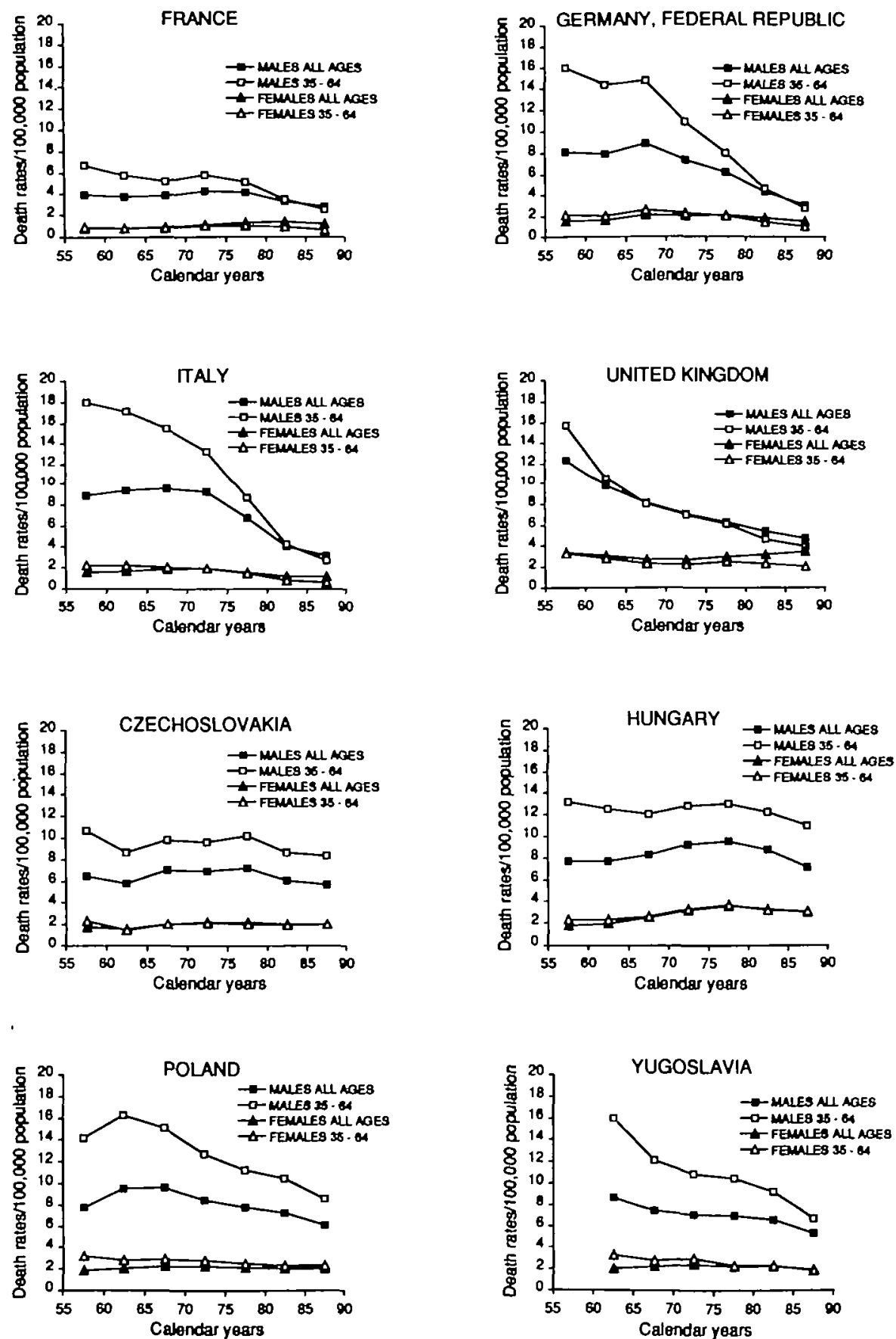

FIGURE 2 Trends in age-standardized (world standard) mortality rates from peptic ulcer in selected European countries. 


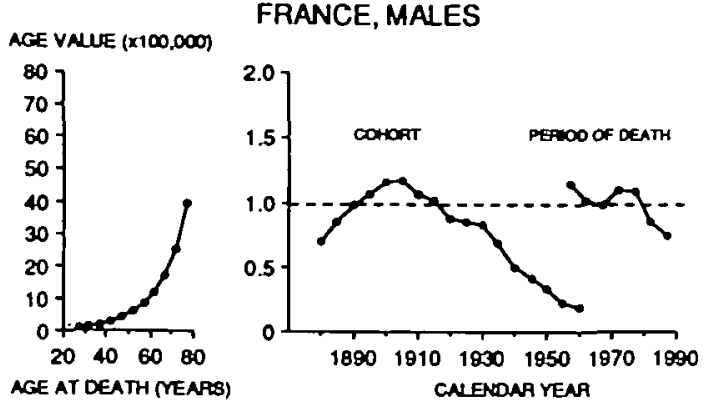

GERMANY FEDERAL REPUBLIC, MALES

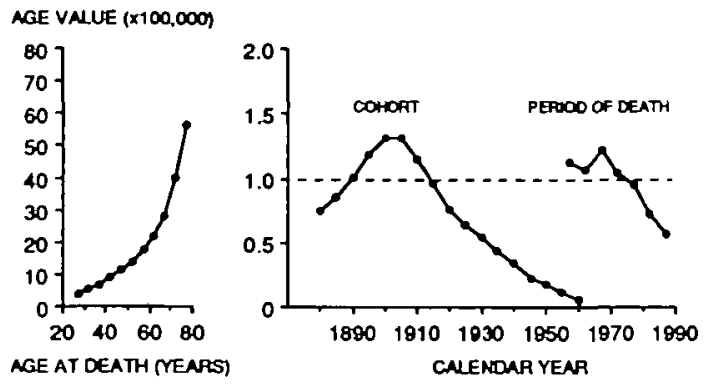

ITALY, MALES

AOE VALUE $(\times 100,000)$
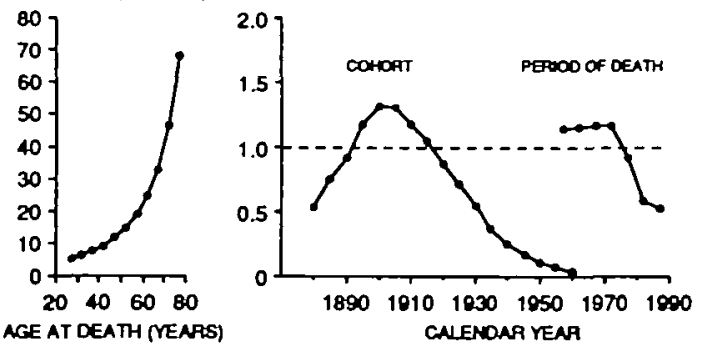

UNITED KINGDOM, MALES

AGE VALUE $(x 100, \infty 00)$

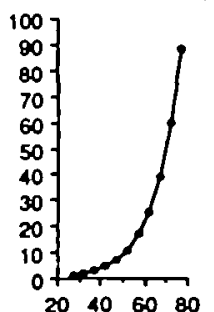

$$
2040 \quad 6080
$$
AGE AT DEATH MEARS)
AGE VAULE ( 100,000$)$

FRANCE, FEMALES
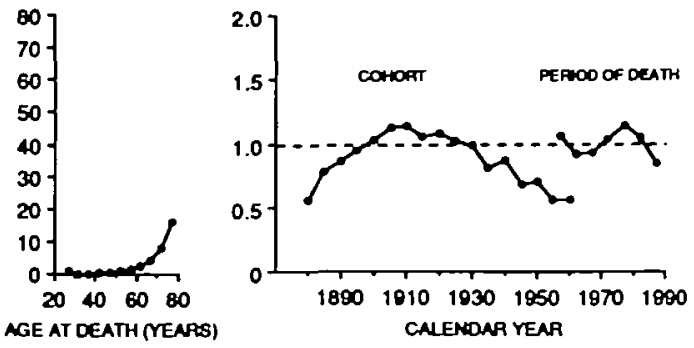

AGE VALUE (x100,000)

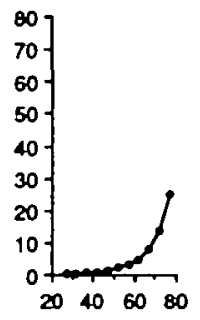

AGE AT DEATH (YEARB)

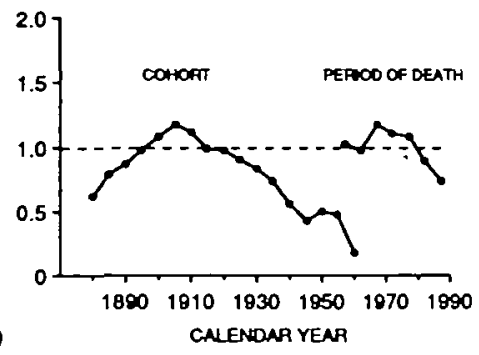

ITALY, FEMALES

AGE VAUE $(\times 100,000)$
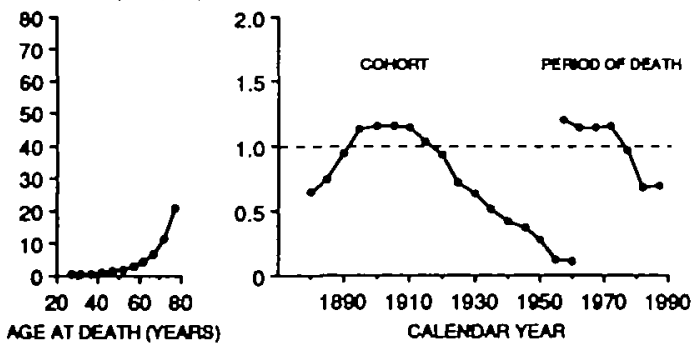

\section{UNITED KINGDOM, FEMALES}

AGE VAUUE $(\times 100,000)$

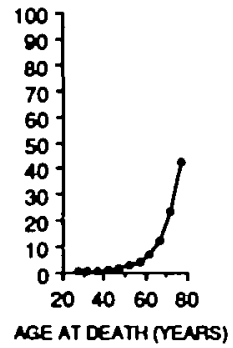

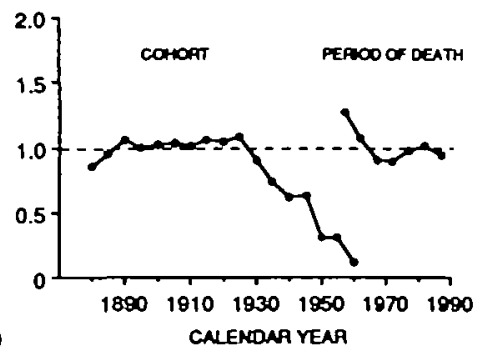

FIGURE 3 Age, cohor of birth and period of death effects from peptic ulcer mortality in selected European countries, derived from a loglinear age-period and cohort madel. ${ }^{21}$ 
FIGURE 3 Continued.

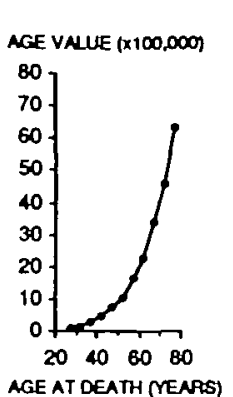

CZECHOSLOVAKIA, MALES

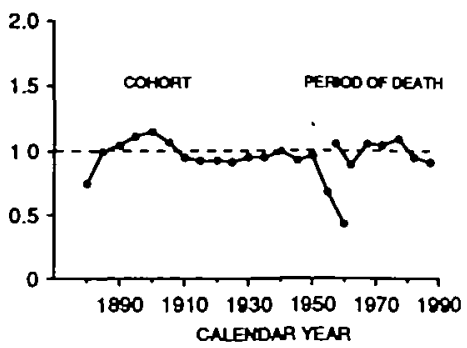

HUNGARY, MALES

AGE VNUEE $(\times 100,000)$

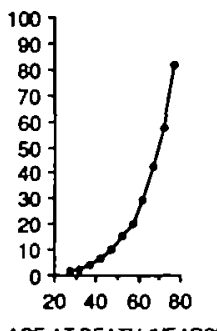

AGE AT DEATH (YEARE)

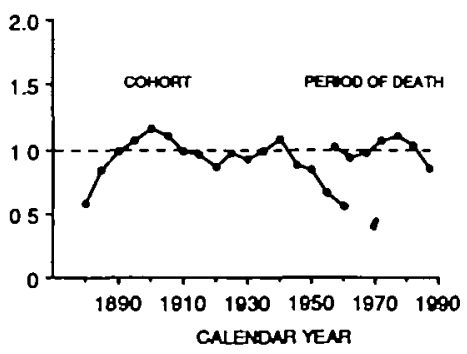

POLAND, MALES

AGE VNUEE $(\times 100,000)$
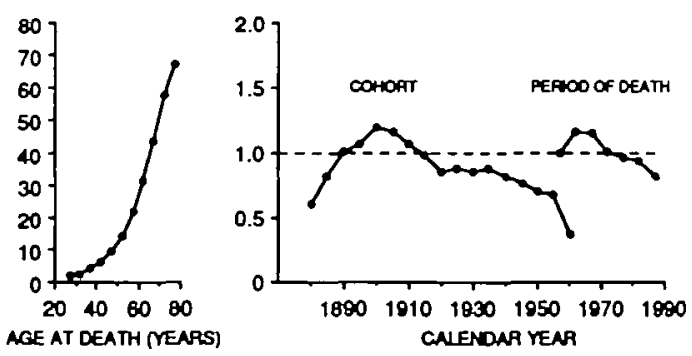

in ulcer mortality, producing a reduction in the complications of the disease (perforated ulcer and haemorrhage), as well as of the consequent surgical procedures and related mortality. ${ }^{14,15,23,24}$ Other factors, however, may have had a favourable impact, including better surgical techniques, broad spectrum antibiotics, and therapeutic endoscopy. 2,25,26

The impact of newer therapies on ulcer mortality was, however, heterogenous in various European countries. In Western Europe, the average fall in ulcer mortality over the last decade approached $50 \%$ among males of all ages and $65 \%$ in middle age, while the corresponding gains in Eastern Europe were only 20\% and $25 \%$, and in females the declines were also appreciably lower in Eastern Europe.

\section{CZECHOSLOVAKIA, FEMALES}
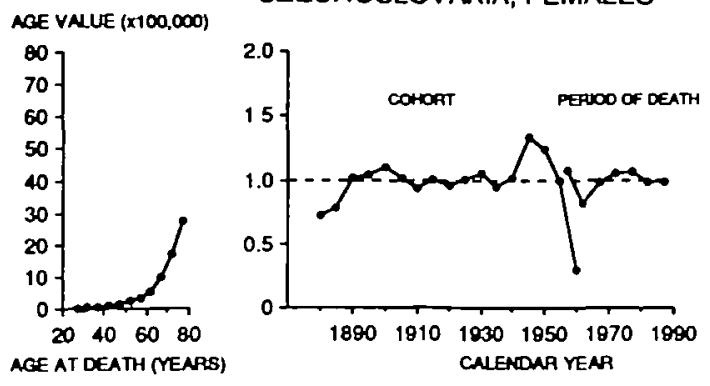

HUNGARY, FEMALES

AGE VNUE $(\times 100,000)$
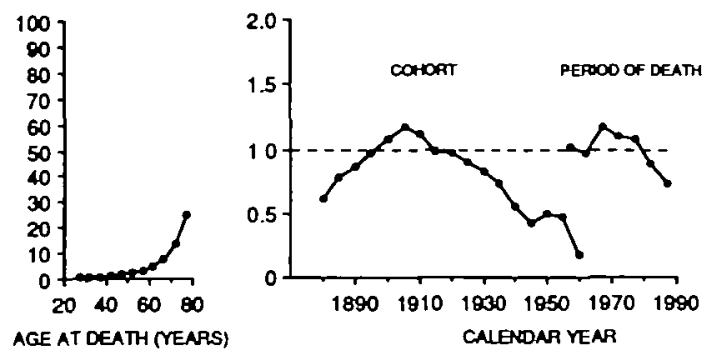

POLAND, FEMALES

AGE VNUE $(\times 100,000)$
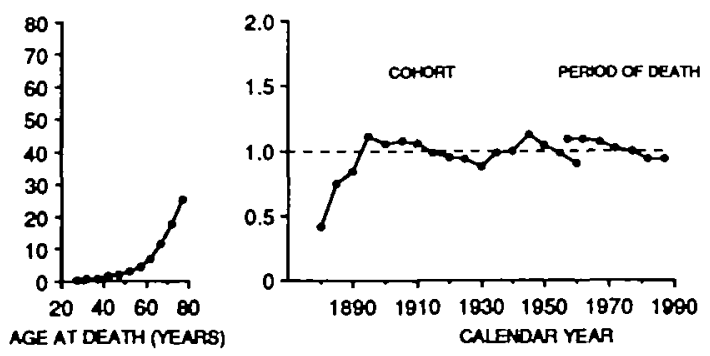

Overall, about 20000 deaths per year were avoided in the whole of Europe in the late 1980s. This major advance, however, cannot totally eclipse a second major message emerging from this report, i.e. that there is ample scope for further improvement in ulcer treatment in Europe through a more widespread and rational application of available treatments. Assuming that the same rate of decline reported in Western Europe could be extended to Eastern countries, a further 5000 deaths per year could have been avoided.

Even in Western Europe some moderate, but continuing decline in ulcer death rates was still apparent in recent years. This would suggest that further improvement is still possible following further therapeutic development ${ }^{27}$ and/or more rational use of drugs in- 
troduced in the 1970s. Assuming that these trends continue in future, it is therefore possible that peptic ulcer will become an avoidable cause of death.

\section{ACKNOWLEDGEMENTS}

This study has been made possible by a grant from the Swiss League against Cancer. Support was also received from the Italian Association for Cancer Research and the Italian League against Cancer. This study was conducted within the framework of the CNR (Italian National Research Council) Applied Projects 'Clinical Application of Oncological Research' and 'Risk factors for Disease'. We thank Mrs H-C Janin for editorial assistance.

\section{REFERENCES}

${ }^{1}$ Susser M, Stein Z. Civilisation and peptic ulcer. Lancet 1962; I: $115-19$.

2 Langman M J S. What is happening to peptic ulcer? $\mathrm{Br}$ Med $J$ 1982; 284: 1063-64.

${ }^{3}$ Sonnenberg A, Moller H, Pace F. Birth-cohort analysis of peptic ulcer mortality in Europe. J Chron Dis 1985; 38: 309-17.

4 Sonnenberg A. Occurrence of a cohort phenomenon in peptic ulcer mortality from Switzerland. Gastroenterology 1984; 86: $398-401$.

${ }^{5}$ Sonnenberg A, Muller H. Cohort and period effects in peptic ulcer mortality from the U.S.A. Gastroenterology 1984; 86: 1261.

${ }^{6}$ Susser M. Period effects, generation effects and age effects in peptic ulcer mortality. J Chron Dis 1982; 35: 29-40.

${ }^{7}$ Wylie C M. The complex wane of peptic ulcer. I. Recent national trends in deaths and hospital care in the United States. $J$ Clin Gastroenterol 1981; 3: 327-32.

${ }^{8}$ Vogt T M, Johnson R E. Recent changes in the incidence of duodenal and gastric ulcer. Am J Epidemiol 1980; 111: 713-20.

${ }^{9}$ Kurata J H, Haile B M. Epidemiology of peptic ulcer disease. Clin Gastroenterol 1984; 13: 289-307.

${ }^{10}$ Coggon D, Lambert P, Langman M J S. Twenty years of hospital admissions for peptic ulcer in England and Wales. Lancet 1981; I: 1302-04.
${ }^{11}$ O'Connor P C, Griffiths K, Shank R G. Trends in peptic ulcer related disease from 1972 to 1980 . Hospital activity analysis data and general practice cimetidine prescribing kevels. Eur $J$ Clin Pharmacol 1983; 24: 435-40.

12 Sonnenberg A. Disability pensions due to peptic ulcer in Germany between 1953 and 1983. Am J Epidemiol 1985; 122: 106-11.

${ }^{13}$ Sterup K, Mosbech J. Trends in the mortality from peptic ulcer in Denmark. Scand J Gastroenterol 1973; 8: 49-53.

14 Bulthuis R, Laing W A. Cost effectiveness of cimetidine. Lancet 1982; 14: 828-29.

15 Quartini A, Negri E, La Vecchia C. Trends in peptic ulcer mortality in Italy, 1955-1985. J Epidemiol Comm Health 1992; 46: 494-97.

16 World Health Organization. International Classfication of Diseases-6th Revision. Geneva: WHO 1950.

${ }^{17}$ World Health Organization. International Classiflation of Diseases-7th Revision. Geneva: WHO, 1957.

18 World Health Organization. Internotional Classification of Diseases-8th Revision. Geneva: WHO 1967.

19 World Health Organization. International Classiffcation of Diseases-9th Revision. Geneva: WHO, 1977.

20 Osmond C, Gardner M J. Age, period and cohort models applied to cancer mortality rates. Stat Med 1982; 1: 245-59.

21 Decarli A, La Vecchia C. Age, period and cohort models : Review of knowledge and implementation in GLIM. Rivista $d i$ Statistica Applicata 1987; 20: 397-410.

22 Baker R J, Nelder J A. The GLIM System Release 3. Oxford, Numerical Algorithms Group, 1978.

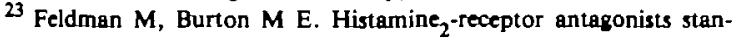
dard therapy for acid-peptic diseases. Part 2: $\mathrm{H}_{2}$ blockers in peptic ulcer disease. $N$ Engl J Med 1990; 323: 1749-55.

24 Langman M J S. Ulcer complications and non-steroidal antiinflammatory drugs. Am J Med 1988; 84: 15-19.

${ }^{25}$ Richardson C T. Gastric ulcer. In : Sleisenger M H, Fordtran J S, (eds). Gastrointestinal Disease : Pathophysiology, Diagnosis, Management, Vol. I 4th edn. Philadelphia: W. B. Saunders, 1989, pp. 879-909.

${ }^{26}$ Soll A H. Duodenal uker and drug therapy. In : Sleisenger $\mathbf{M ~ H}$, Fordtran J S, (eds). Gastrointestinal Disease: Pathophysiology. Diagnasis, Monagement. Vol. J. (4th edn). Philadelphia: W. B. Saunders, 1989, pp. 814-79.

${ }^{27}$ Langman M J S. Omeprazole for resistant peptic ulcers and severe oesophageal reflux disease. Br Med J 1991; 303: 481-92.

(Revised version received July 1992) 